\title{
Impactos socioambientais nas construções de barragens hidrelétricas
}

\author{
Alessandra Renata Freitas Fontes ${ }^{1}$ \\ Dante Severo Giudice ${ }^{2}$
}

\begin{abstract}
Resumo: $O$ presente artigo possui como objetivo geral definir e traçar análise sob a implantação de barragens hidrelétricas no Brasil. O estudo sobre os impactos causados por tais construções é realizado por intermédio do prisma econômico, social e ambiental. Para o estudo, parte-se da vertente jurídicosociológica e utiliza-se a metodologia de pesquisa teórica, a partir de uma revisão bibliográfica pautada em documentos que evidenciam o tema exposto. Como resultado da pesquisa, infere-se que existe na construção de tais empreendimentos uma assimetria de poder, que origina uma apropriação social sobre osconflitos socioambientais, na medida em que a utilização dos espaços ambientais ocorre em detrimento do uso que outros segmentos sociais fazem do território. Dessa maneira, constata-se que barragens hidrelétricas são geradoras de injustiça ambiental, visto que são construídas e implementadas com a finalidade precípua de beneficiar determinados setores econômicos, em prol de direitos fundamentais da comunidade direta e indiretamente afetada.
\end{abstract}

Palavras chave: Atingidos por barragens; Barragens hidrelétricas; Direitos Humanos violados; Impactos socioambientais.

\section{Social and environmental impacts on the construction of hydroelectric dams}

\begin{abstract}
The present article has as its general objective to define and outline analysis under the implementation of hydroelectric dams in Brazil. The study on the impacts caused by such constructions is carried out through the economic, social and environmental prism. For the study, it starts from the legalsociological aspect and uses the theoretical research methodology, based on a bibliographic review based on documents that highlight the exposed theme. As a result of the research, it is inferred that there is an asymmetry of power in the construction of such enterprises, which leads to a social appropriation of socio-environmental conflicts, insofar as the use of environmentalspaces occurs to the detriment of the use that other social segments make of territory. Thus, it appears that hydroelectric dams generate environmental injustice, since they are built and implemented with the primary objective of benefiting certain economic sectors, in favor of the rights and fundamentals of the community directly and indirectlyaffected.
\end{abstract} rights violated.

Key words: Hydroelectric dams; Socio-environmental impacts; Affected by dams; Human

\footnotetext{
${ }^{1}$ Mestranda do PPGPA da UCSAL E-mail: alessandrafontess@hotmail.com

${ }^{2}$ Dante Severo Giudice (Orientador). Prof. Dr. do PPGPA da UCSAL. Mestrado em Planejamento Ambiental, Universidade Católica do Salvador, Instituto Nacional de Ciência e Tecnologia em Estudos Interdisciplinares e Transdisciplinares em Ecologia e Evolução (IN-TREE). Universidade Federal da Bahia. E-mail: dante.giudice@pro.ucsal.br
} 


\section{Introdução}

Analisando-se pelo aspecto econômico, as barragens são fontes importantes de energia para países com alto potencial hidrelétrico, como é o caso do Brasil. A partir da análise de dados, verifica-se que das grandes bacias hidrográficas distribuídas pelo mundo, poucas escaparam de um sistema de represamento (COELHO, 2008). Na categoria dos países com maior produção de energia hidrelétrica, o Brasil aparece em segundo lugar, possuindo atualmente 1340 usinas utilizadoras de recursos hídricos, que são responsáveis por gerar 104.599.212 KW de energia elétrica, totalizando o percentualde 60,7045 da matriz energética brasileira, segundo informações fornecidas pela Agência Nacional de Energia Elétrica - ANEEL (ANEEL, 2019).

Tais construções produziram deslocamentos estimados de, no mínimo, um milhão de pessoas, e inundaram cerca de 3,4 milhões de hectares das terras produtivas (SANTOS, 2008) do país. Sendo assim, é possível afirmar que a construção de barragens hidrelétricas representam investimentos financeiros expressivos no país, sendo, contudo, fontes causadoras de extensos impactos de cunho tanto ambiental, como social.

A partir da metade do século XX, o projeto de crescimento, expansão e desenvolvimento brasileiro foi condicionado à expansão da matriz energética, a solução encontrada pelo poder público foi a construção de barragens hidrelétricas de grande porte, imensamente destrutivas do ponto de vista socioambiental (FONSECA, 2013).

Analisando-se pelo prisma ambiental, é possível afirmar que as hidrelétricas provocam consequências irreparáveis. Em suma, são responsáveis pelo alagamento de grandes parcelas de floresta nativa, pelo desvio e alteração do curso de rios e pela emissão de metano na atmosfera, dentre outros impactos no ecossistema, na biodiversidade regional e na dinâmica geral do solo e dos rios (FONSECA, 2013), bem como na organização sócio- histórica e econômica das populações atingidas.

Ademais, vislumbra-se que alguns autores afirmam que o nível de produção de energia hidrelétrica de um país constitui um indicador de sustentabilidade ambiental. Tal afirmação no contexto da sociedade brasileira pode contribuir para a crença de que o país caminha no sentido de um "desenvolvimento sustentável”, uma vez que 70,5\% da capacidade instalada no país provêm de fonte hidráulica (ZHOURI,2013).

Contudo, estudos apontam que barragens hidrelétricas contribuem para a intensificação do efeito estufa no país, visto que liberam gases em razão da decomposição do material orgânico em seus reservatórios, tais como o dióxido decarbono (CO2), o metano (CH4), e o óxido nitroso (N2O) (SANTOS, 2008). Esses gases possuem origem biogênica, e estudos 
científicos indicam que estes interagem com a radiação infravermelha na atmosfera, causando a intensificação do efeito estufa natural (SANTOS, 2008).

Sob o prisma social, constata-se que a construção de barragens e reservatórios hidrelétricos tem como consequência o deslocamento de milhares de pessoas, visto quea água represada submerge grandes áreas, inundando casas, plantações, pastos, bem como todo o entorno da região onde o empreendimento é implementado. À vista disso, emergem conflitos entre as populações ribeirinhas, que querem resguardar a terra como patrimônio da família e da comunidade, defendido pela memória coletiva e por regras de uso e compartilhamento dos recursos, e o setor elétrico que a partir de uma ótica de mercado, entende o território como propriedade, e, como tal, uma mercadoria passívelde valoração monetária, sem levar em conta o sentimento de pertencimento da população (FONSECA, 2013).

Ademais, reservatórios, que são criados em conjunto com as barragens, oferecem riscos à saúde humana, devido à água estagnada, que atrai insetos transmissores de doenças tropicais, tais como a malária (FONSECA, 2013).

Diante disso, infere-se que existe na construção de tais empreendimentos uma assimetria de poder, que origina uma apropriação social sobre os recursos naturais, gerando, por conseguinte, uma má distribuição ecológica, bem como conflitos socioambientais, na medida em que a utilização dos espaços ambientais ocorre em detrimento do uso que outros segmentos sociais fazem do território (MARTINEZ,1999).

Nesse quadro, constata-se que barragens hidrelétricas são geradoras de injustiça ambiental, visto que são construídas e implementadas com o objetivo precípuo de beneficiar determinados setores econômicos, em prol de direitos fundamentais da comunidade direta e indiretamente afetada.

\section{O que são barragens hidrelétricas?}

A priori, cumpre conceituar o termo Barragens Hidrelétricas. Barragens Hidrelétricas são estruturas, constituídas de concreto, enroncamento ${ }^{3}$ e solo, que servem para represar a água e

\footnotetext{
3 "Barragem de terra/enrocamento é um aglomerado de terra e pedras usadas para sustentação de uma barragem. As barragens de terra/enrocamento destinadas ao armazenamento permanente de água devem possuir um elevado grau de estanqueidade (presença de um elemento de vedação). Estas barragens são construídas, via de regra, com materiais oriundos de áreas de empréstimo, devidamente selecionadas, que são transportados, lançados e compactados, com equipamentos especiais, sob rigoroso processo de controle executivo. Possuem comumente um sistema de drenagem interna eficiente (presença de um elemento drenante) e coeficientes de segurança elevados, tanto para a possibilidade de ocorrência de erosão interna como para possibilidade de ruptura por cisalhamento (presença de um elemento estabilizante). As barragens de terra/enrocamento devem ter sistemas de extravasamento bem dimensionados que lhes confiram elevados coeficientes de segurança contra a possibilidade de galgamento" (GOMES et,al. 2006).
} 
obter o desnível, de aproximadamente $120 \mathrm{~m}$ (queda bruta nominal), o que permite a operação das turbinas (BARRAGEM..., 2019).

Pode-se afirmar que o seu objetivo precípuo é conter o fluxo de um rio. São projetadas para armazenar o máximo de água possível, provenientes tanto da água da chuva, como da captação caudal do rio represado.

São construídas a partir da união das duas margens do rio, aprisionando a água na albufeira (represa artificial das águas correntes ou pluviais). A sua estrutura é composta de tomadas de água, localizadas na parte superior da barragem principal, que é formada por comportas, que permitem que a água, ao passar por elas e pelos condutos forçados, alcance a caixa espiral, fazendo a turbina girar, produzindo, por conseguinte, energia (COELHO, 2008).

Ademais, as barragens são agrupadas em duas categorias principais: barragens do tipo com reservatório e barragens a fio d'água.

Sendo assim, as barragens do tipo com reservatório represam água atrás da barragem para armazenamento sazonal, anual e, em alguns casos, plurianual do fluxo do rio (SCHREIBER,1977), enquanto as barragens "a fio d'água" (represas e diques, barragens de desvio) não dispõem de reservatório de água ou têm reservatórios pouco relevantes quando comparados com a vazão.

De acordo com o entendimento de pesquisadores "não é possível estabelecer regras fixas sobre o planejamento porque as condições topográficas, hidrográficas, econômicas e às vezes políticas são diferentes em cada bacia hidrográfica" (SCHREIBER,1977). É possível vislumbrar que uma barragem é fruto de um processo de planejamento e construção que se insere em um conjunto de condicionalidades e contingências que se apresentam de maneiras variadas, de acordo com a localidade, e vão além do planejamento exclusivo do setor elétrico e de seus especialistas técnicos (SNEDDON, 2015).

\section{Histórico da construção de barragens/reservatórios no Brasil}

Analisando-se dados históricos, é possível vislumbrar que na década de 1980, mais especificamente no ano de 1987, um projeto de expansão da matriz energética brasileira foi elaborado pelo Ministério das Minas e Energia (FEARNSIDE, 2015), por meio da ELETROBRÁS. Verifica-se a construção em massa de barragens hidrelétricas nesse período, dentre elas a barragem de Tucuruí, no Pará; de Itaipu, que integrava Brasil e Paraguai; e, também, 
as barragens de Sobradinho e Itaparica, no Nordeste e de Itá e Machadinho, na região sul do país (ALVES, 2015).

Denominado Plano 2010, o documento continha informações sobre a previsão de construção de barragens em todo o País até o ano 2010, bem como uma listagem de outras barragens planejadas, sem fazer alusão à data de conclusão das mesmas. Ao total, o documento previa a construção de 297 barragens no País como um todo, das quais 79 seriam na Amazônia. $\mathrm{Na}$ região da Amazônia, a estimativa de inundação era de 10 milhões de hectares, o que representa 2\% da Amazônia Legal ou 3\% da área originalmente florestada na região (ALVES, 2015). Devido à extensão dos danos previstos, o documento foi amplamente rechaçado e criticado pelos ambientalistas e profissionais especializados na área.

À época da implementação de tal projeto o processo de construção de barragens hidrelétricas no Brasil era essencialmente desimpedido por exigências de licenciamento ambiental, visto que embora houvesse no país legislação que fazia alusão à necessidade de estudos ambientais (Lei 6.938 Federal, editada em 31 de agosto de 1981), tal lei possuía aplicabilidade limitada, sendo regulamentada pela Resolução 001 do CONAMA, no dia 23 de janeiro 1986 (ALVES, 2015).

Doravante, tornaram-se obrigatórios para a construção de projetos de grande infraestrutura, e causadores impactos ambientais, como a construção de barragens hidrelétricas, o Estudo de Impacto Ambiental (EIA) e o Relatório sobre Impacto Ambiental (RIMA) (FEARNSIDE, 2016).

À época da propositura da legislação, pautado em um discurso desenvolvimentista, o sistema brasileiro de licenciamento ambiental, ainda incipiente, era constantemente violado, existindo inúmeras tentativas de implementação de grandes projetos sem a realização de estudos ambientais efetivos. A suposição de muitos era queprojetos prioritários de desenvolvimento, na prática, poderiam ser implementados sem a observância das exigências ambientais estabelecidas na legislação (FEARNSIDE, 2015).

Com a análise de dados sucedida na presente pesquisa, verifica-se que tal pensamento perdura até os dias atuais, contudo, este era muito mais evidente e enraizado no processo de tomada de decisões durante os primeiros anos de licenciamento ambiental no Brasil (FEARNSIDE,2016).

Na atualidade, encontra-se em vigor o Plano Nacional de Energia 2030 (PNE 2030), que apresenta o potencial de aplicação de medidas de eficiência energética no Brasil até o ano de 2030. A previsão realizada pela Empresa de Pesquisa Energética (EPE) é de implementação e 
operação de cerca de 34 novas usinas hidrelétricas no país. Dentre esse total, a estimativa é de que 15 usinas serão instaladas na região da Amazônia Legal (ANEEL, 2019).

Com o exame dos dados históricos referentes à construção de barragens hidrelétricas no Brasil, depreende-se que a implementação de grandes empreendimentos geradores de energia hidrelétrica não estão relacionados à construção de sociedades mais justas, democráticas e sustentáveis. Ao revés, tais obras são implementadas visando precipuamente interesses econômicos, pautados em incentivos fiscais e flexibilização de políticas socioambientais, proporcionando a mercantilização dos recursos ambientais, e agravando a precarização da vida de pequenas populações já excluídas e invisibilizadas social, política e culturalmente. Sendo assim, vislumbra-se no processo histórico de construção de barragens hidrelétricas brasileiras, a prevalência de discursos e histórias oficiais que privilegiam os benefícios deste modo de produção energética, encobrindo os danos e as injustiças sociais cometidas (GIONGO, 2018).

\section{Impactos causados pela construção de barragens}

\section{Impactos ambientais}

Traçando análise sob o prisma ambiental, constata-se que a construção de barragens hidrelétricas acarretam sérias consequências para o meio ambiente. Tais obras são justificadas socialmente por serem fontes renováveis de energia, como também por contribuírem para a regularização da vazão dos rios (evitando enchentes), contudo são responsáveis pelo alagamento de grandes parcelas de floresta nativa da região afetada, pelo desvio e alteração do curso de rios, pela emissão de metano na atmosfera, entre outros impactos no ecossistema e na biodiversidade da localidade direta e indiretamente afetada (ECODEBATE, 2013).

Dentre os principais impactos ambientais, destacam-se: a) os impactos negativos na biodiversidade da região afetada, seja com relação à biodiversidade situada na área alagada, seja quanto às espécies situadas no regime fluvial que a circunda; b) usinas hidrelétricas não são fontes limpas de energia, sendo grandes emissoras de metano, gás que contribui, em forma mais acentuada que o CO2, para o advento das mudanças climáticas e do efeito estufa (FEARNSIDE, 2016).

Em razão de constituírem uma barreira física, barragens e reservatórios podem influenciar direta e indiretamente o padrão de migração de diversas espécies de animais, e promover a alteração da composição da fauna da localidade atingida. Ademais, o represamento das águas 
pode causar alteração na biodiversidade e na equitabilidade dos sistemas, o que pode ocasionar a predominância de espécies, não existente anteriormente, ou causar a eliminação de espécies com maior exigência de hábitat, tendo em vista que estas não suportam grandes alterações naturais. Sendo assim, verifica-se que a construção de barragens e reservatórios acarretam mudanças das características bióticas e abióticas da localidade atingida, o que causa alteração do equilíbrio ambiental (ZAGONEL, 2009).

Quanto à emissão de gases causadores de efeito estufa, cumpre repisar que no caso das barragens e reservatórios brasileiros, o gás carbônico (CO2) é emitido pela decomposição das árvores situadas acima da lâmina d'água, visto que a vegetação não é retirada antes da inundação do local do reservatório, enquanto o metano (CH4) éliberado pela decomposição em condições anaeróbicas, que ocorre no fundo do reservatório (FEARNSIDE, 2008) ${ }^{4}$

Destarte, a construção de barragens e reservatórios hidrelétricos acarreta o rompimento do equilíbrio longitudinal do rio/bacia hidrográfica onde fora instalado o empreendimento. Isto acontece em razão do barramento do canal fluvial interferir no sistema lótico do rio (correntezas) o que acarreta na transformação das suas características, tornando as águas lênticas/semi-paradas no reservatório ou barragem (CUNHA, 2002).

Sendo assim, constata-se que tais interferências suscitam uma série de impactos fluviais, geomorfológicos, na fauna e na flora da região atingida, bem como na atmosfera. Repise-se que a depender da magnitude e da área de abrangência de tais empreendimentos, estes impactos são irreparáveis ao ecossistema local, bem como à biodiversidade.

\section{Impactos socioambientais}

No que tange aos conflitos socioambientais na construção de barragens hidrelétricas no Brasil, pode-se afirmar que estes resultam do choque de interesses existentes entre agentes que possuem interesses antagônicos.

De maneira geral, a construção de barragens hidrelétricas se justifica socialmente pelo discurso do estímulo à geração de empregos, do acesso à eletricidade, do desenvolvimento econômico regional e nacional, e da geração de energia limpa e renovável.

\footnotetext{
4 “O metano é liberado através de vários caminhos, inclusive por bolhas e difusão pela superfície, e é liberado no transcurso da água pelas turbinas e vertedouros. A vegetação herbácea, de fácil decomposição, cresce rapidamente na zona de deplecionamento, ou de drawdown, que é a área do fundodo reservatório que fica exposta quando o nível da água é periodicamente rebaixado. Quando o nível da agua sobe, a biomassa se decompõe no fundo do reservatório, produzindo metano. O recrescimento da vegetação na zona de depleciamento do reservatório, a cada ano, remove gás carbônico da atmosfera pela fotossíntese, re-emite o carbono na forma de metano quando a vegetação é inundada. O reservatório então, age como uma verdadeira fábrica de metano, convertendo continuamente $\mathrm{CO} 2 \mathrm{em}$ CH4” (FEARNSIDE, 2008).
} 
Contudo, à medida que são idealizados como fundamentais e necessários para o desenvolvimento nacional e regional, estes não se preocupam em trazer em seu bojo estudos e análises técnicas de viabilidade e conformidade plausíveis e suficientes para atenuar os efeitos negativos da implantação de tais projetos nos âmbitossociocultural, ambiental e econômico (FEARNSIDE, 2008).

Deste modo, no processo de planejamento e construção de barragens hidrelétricas temse de um lado as forças do mercado, que buscam constantemente transformar o espaço e os recursos naturais em mercadoria, passíveis de apropriação privada para geração de energia elétrica, e do outro, as comunidades direta e indiretamente atingidas, que perdem suas referências construídas mediante as relações estabelecidas com o território inundado (BRANCO, 1997).

Com a construção das barragens, o espaço físico socialmente construído perderá as referências sedimentadas pelas relações de pertencimento estabelecidas, durante gerações, no cotidiano de muitos, e seus múltiplos significados para a população atingida não serão considerados pela avaliação tecnocrática dos empreendedores (BRANCO, 1997).

A construção de barragens e reservatórios hidrelétricos provoca o deslocamento compulsório da população da área que será atingida direta e indiretamente pela inundação. Em geral, os mais prejudicados são índios, quilombolas, camponeses e populações mais carentes. Cerca de 34 mil km² de terras foram submersas pelas águas dos reservatórios artificiais no Brasil, havendo o deslocamento compulsório de aproximadamente 1 milhão de pessoas, sendo que destas, apenas 30\% foram devidamente indenizadas (ROGERIO, 2019).

Conforme explicitado anteriormente, as águas represadas pela construção de barragens hidrelétricas são responsáveis pela inundação de terras anteriormente habitadas pela população originária local. A inundação representa, para as comunidades atingidas direta ou indiretamente, a destruição de projetos de vida, visto que a expulsão do imóvel em que residiam originariamente não vem acompanhada de medidas compensatórias que reconstituam ou garantam a manutenção de suas condições econômicas, sociais e culturais existentes antes da implantação da barragem (BRANCO,1997).

Dessa maneira, para a população atingida pela construção de barragens e reservatórios hidrelétricos, essas obras representam além da perda de suas casas, empregos e modo de subsistência, a perda do direito fundamental ao acesso às suasreferências sociais e culturais, as quais estão intimamente ligadas ao território que habitavam (MAB, 2012).

Sendo assim, depreende-se que o discurso hegemônico favorável à construção das barragens e reservatórios hidrelétricos, ancorado na justificativa de que tais obras possuem utilidade pública, bem como na ideia de desenvolvimento nacional a partir da expansão do setor 
elétrico, busca, em verdade, tornar invisível, ou como fato completamente natural e necessário ao progresso, a supressão dos direitos fundamentais dos atingidos, bem como o sofrimento dos mesmos.

Contudo, tais brasileiros, direta ou indiretamente atingidos pelas construções das barragens hidrelétricas, não se opõem ao progresso nacional. Todavia, seus direitos fundamentais não podem ser desrespeitados e suprimidos em prol de tal crescimento.Em suma, devem ser preservados o direito constitucional à moradia e à proteção ao patrimônio histórico e cultural dessas comunidades, bem como tudo que represente a identidade do povo ou grupo que habite o perímetro da localidade atingida.

Existe no ordenamento jurídico pátrio o Decreto-Lei n 3.365, de 1941, que dispõe sobre as desapropriações por utilidade pública. Tal legislação preceitua que "mediante declaração de utilidade pública, todos os bens poderão ser desapropriados pela União, pelos Estados, Municípios, Distrito Federal e Territórios” (BRASIL, 1941). Traçando análise da legislação supracitada, verifica-se a soberania da perspectiva da utilidade pública e do bem maior, sobre os direitos fundamentais da população atingida, bem como a sobreposição da lógica compensatória financeira, como única forma mitigadora dos impactos causados. À vista disso, verifica-se que tal legislação deixa de considerar aspectos relacionados à saúde, ao meio ambiente, ao trabalho e aos direitos básicos dos desapropriados (BRASIL, 1941).

Hodiernamente inexiste no ordenamento jurídico pátrio legislação que regulamente e defina o significado e a abrangência do 'atingido por barragem', bem como inexiste marco legal que discipline as especificidades do deslocamento de populações para dar lugar aos reservatórios das barragens hidrelétricas. Sendo assim, cabe às construtoras e aos interessados na construção dos empreendimentos, classificar quem são os atingidos por barragens, bem como disciplinar a extensão das medidas mitigadoras e reparações às populações atingidas (MAB, 2005).

Geralmente, o conceito de 'atingido por barragem' é definido pelos interessados como: proprietário de terra com título de posse devidamente regularizado. Sendo assim, com raras exceções, os interessados na construção de barragens hidrelétricas declaram

como passível de reparação indenizatória, os atingidos que não se enquadrem no critério supracitado (MAB, 2005).

Contudo, é de fácil constatação que grande parte dos atingidos pela construção de barragens hidrelétricas, quais sejam, camponeses, trabalhadores sem-terra, posseiros, arrendatários, meeiros, comunidades indígenas e quilombolas não possuem o documento formal capaz de comprovar a propriedade da terra, fato que inviabiliza a indenização (MAB, 2008). 
Insta salientar que as indenizações concedidas aos atingidos pelas construções de barragens hidrelétricas são avaliadas e determinadas de acordo com os bens materiais ou benfeitorias existentes nas terras atingidas.

Contudo, grande extensão das regiões atingidas são constituídas de pequenos roçados e casas de "pau-a-pique", sendo, por conseguinte, estabelecidos os valores monetários das indenizações de acordo com o valor desses materiais. À vista disso, são corriqueiros relatos de indenizações no valor de $\mathrm{R} \$ 800,00, \mathrm{R} \$ 700,00, \mathrm{R} \$ 300,00, \mathrm{R} \$ 100,00$ ou até mesmo $\mathrm{R} \$ 30,00$, distribuídos às famílias atingidas, para que com esse dinheiro, se mudem e reconstruam a vida em outra região (MAB, 2012).

Desta forma, depreende-se que além dos atingidos pelas barragens terem seu direito fundamental à moradia suprimido, não lhes é ofertado nem pelos empreendedores e nem pelos órgãos governamentais, subsídios para que consigam reconstruir sua vida com um mínimo de dignidade em outras regiões, situação que viola, claramente, os direitos humanos fundamentais e sociais desta população, tais como direito à informação e à participação, direito de ir e vir, direito à justa negociação e ao tratamento isonômico, direito à moradia adequada, direito a um ambiente ecologicamente equilibrado e saudável, direito à saúde, dentre outros (FEARNSIDE, 2014). Sendo assim, vislumbra-se que a injustiça social e ambiental presente o contextoda construção de barragens e reservatórios hidrelétricos é produzida tanto pelas empresas responsáveis pelas obras como pelo Estado, que deixa de proteger a populaçãodiante da inexistência de políticas públicas e práticas institucionais, preferindo se omitir diante da situação (MAB, 2008).

No que tange aos órgãos ambientais, vislumbra-se que existe uma dualidade na maneira como são vistos pela sociedade brasileira. Isto porque, em determinadas situações, tais órgãos são vistos como atores-chave na luta contrária à construção das barragens, em prol de interesses socioambientais. Contudo, em determinadas situações,

tais órgãos são vistos como ambíguos e incoerentes, visto que são eles os próprios responsáveis pela aprovação dos licenciamentos ambientais para a construção destas mesmas barragens (FEARNSIDE, 2008).

Essa ambiguidade/incoerência está intimamente relacionada com a percepção de que as relações intragovernamentais, e a tomada de decisões, em relação à construçãode barragens e reservatórios hidrelétricos, são marcadas por uma assimetria de poder. Depreende-se que os interesses socioambientais são, constantemente, subjugados por interesses econômicos, representados por agências do setor elétrico e por grupos econômicos privados (FEARNSIDE, 2014). 
Tal assimetria é responsável pelas falhas no fluxo de informações entre agências do setor elétrico e do setor ambiental, podendo ser considerada como um fator determinante para que as análises governamentais sobre os custos e benefícios desses empreendimentos sejam projetadas para atender, de maneira prioritária, a interesses de cunho econômico. A baixa qualidade dos estudos de viabilidade tem levado a investimentos ineficientes (ou mesmo ineficazes) e a elevados custos sociais (FOLHES, 2016).

No tocante ao licenciamento ambiental para a construção de tais empreendimentos, verifica-se que a viabilidade ambiental de tais projetos tem se apoiado cada vez mais nas condicionantes ambientais e menos na avaliação de viabilidade ambiental, fase crucial do processo de tomada de decisão, em que deveriam ser consideradas alternativas tecnológicas e de localização, impedindo-se a implantação de projetos pouco viáveis ou mesmo inviáveis do ponto de vista socioambiental (SOUZA JÚNIOR, 2016).

Isto posto, percebe-se que as decisões sobre as liberações de tais obras não são técnicas e nem acontecem em ambiente democrático, sendo, por conseguinte, decisões políticas tomadas por órgãos governamentais submissos aos interesses econômicos do setor privado (SOUZA JÚNIOR, 2016).

Sendo assim, constata-se que a falha no diálogo entre os diversos órgãos governamentais ocasiona a dissociação entre o planejamento da expansão hidrelétrica no país e o projeto constitucional socioambiental. Os enormes prejuízos são ônus que acabam sendo suportados por toda a sociedade, revelando a importância da adoção de instrumentos de planejamento ambiental estratégico. As reconhecidas falhas no licenciamento ambiental e a sistemática violação de direitos humanos na instalação de tais empreendimentos deveriam levar ao aperfeiçoamento dos procedimentos, com vistas à garantia de direitos, e não à sua flexibilização (OMOTO, 2016).

Ao revés disso, relatos atuais apontam para uma forte ofensiva das empresas do setor elétrico contra os atingidos pela construção de barragens, bem como contra militantes sociais e defensores dos direitos humanos destas populações impactadas. É possível observar que à medida que a resistência em oposição ao atual modelo de expansão energética do país vai se tornando mais contundente, intensificam-se as ações de força da policial contra os atingidos (FOLHES, 2016).

Tais repressões ostensivas e violentas são visualizadas nas reintegrações de posse, nas ações para dispersar manifestações em rodovias, nas invasões e destruição de acampamentos, bem como nas audiências públicas oficiais onde são discutidos os projetos de construção das barragens, quando os atingidos são impedidos de se expressar ou expulsos de forma abrupta e violenta do local da audiência (FEARNSIDE, 2014). Diante disso, é possível observar que até os 
dias atuais são mantidas as diretrizes legais e políticas ostensivas implementadas no período da Ditadura Militar, nas quais imperam o uso da força policial e da apropriação dos territórios sem considerar a participação democrática da população atingida (OMOTO, 2016).

Tais diretrizes se materializam faticamente na retirada e expropriação dos meios de vida e subsistência das populações afetadas pelo represamento das águas, na negação e violação dos direitos humanos, especialmente no que tange aos diretos democráticos, econômicos, sociais, culturais e ambientais destas populações, na utilização da violência policial e até de tropas do exército para guarnecer os canteiros de obras e dispersar manifestações populares, bem como pela perseguição política, tentativas de criminalização e prisões arbitrárias de militantes sociais e líderes que organizam a resistência destas comunidades (SOUZA JÚNIOR, 2016).

\section{Considerações finais}

Nas linhas expostas acima buscou-se conceituar e analisar as barragens hidrelétricas brasileiras por intermédio dos prismas econômico, social e ambiental. É possível vislumbrar que a produção de energia que tem como fonte as barragens hidrelétricas é considerada, por muitos, como um modelo energético limpo, viável e renovável. Ademais, constata-se que o Brasil possui um potencial energético hidrelétrico de grande monta, bem como que cerca de $90 \%$ da eletricidade consumidano país é oriunda da produção hidroelétrica.

Além disso, depreende-se que o discurso pró-hidreletricidade é composto de argumentos de cunho ambiental e social, pautados na ilusão de melhoria da qualidade de vida e de desenvolvimento local e nacional, bem como na promessa de suposta geração de empregos e da expansão da rede elétrica, que em tese, deveria ser precursora do progresso para as comunidades mais isoladas.

Contudo, apesar do discurso desenvolvimentista e de suposta sustentabilidade, conclui-se que tais argumentos são incoerentes. No que tange à suposta sustentabilidade, resta evidenciado que as construções de barragens hidrelétricas contribuem para a intensificação do efeito estufa no país, pois liberam gases em razão da decomposição do material orgânico em seus reservatórios, tais como o dióxido de carbono (CO2), o metano $(\mathrm{CH} 4)$, e o óxido nitroso $(\mathrm{N} 2 \mathrm{O})$. Além disto, conclui-se que os reservatórios de água impactam diretamente a fauna e a flora das localidades atingidas em razão do alagamento da região, alterando drasticamente o regime hidrológico local e, consequentemente, influenciando negativamente todo o ecossistema. 
No tocante ao aspecto social, vislumbra-se com clareza que a construção de tais empreendimentos hidrelétricos não trazem às regiões atingidas o prometido desenvolvimento, sendo responsáveis por realizar a submersão dos territórios e o consequente deslocamento compulsório das comunidades atingidas, inviabilizando os modos de vida de povos ribeirinhos e tradicionais por várias razões, explicitadas pormenorizadamente no presente artigo.

Sendo assim, apesar do modelo de produção hidrelétrico ser o modo de produção hegemônico brasileiro, depreende-se que os impactos ambientais e sociais são extremamente danosos às comunidades atingidas, em especial aos indígenas, grupo diretamente atingido pela construção de barragens hidrelétricas, num processo repleto de falhas, devendo serem amplamente considerados no momento da tomada de decisões.

Além disto, conclui-se que existe na construção de tais empreendimentos uma assimetria de poder, que origina uma apropriação social sobre os recursos naturais, gerando, por conseguinte, uma má distribuição ecológica, bem como conflitos socioambientais, na medida em que a utilização dos espaços ambientais ocorre em detrimento do uso que outros segmentos sociais fazem do território.

À vista disso, constata-se que barragens hidrelétricas são geradoras de injustiça ambiental, posto que são construídas e implementadas com o objetivo precípuo debeneficiar determinados setores econômicos, em prol de direitos fundamentais da comunidade direta e indiretamente afetada.

\section{Referências}

ALVES, S. F. S. Movimento dos Atingidos por Barragens: perspectivas teóricas de lutas práticas. Revista Café com Sociologia. Vol. 4, No. 1. Jan - Abr, 2015. Disponível em: https://revistacafecomsociologia.com/revista/index.php/revista/article/view/367/. Acesso em 01 de março de 2018.

ANEEL. Matriz de energia elétrica. Disponível em

<http://www2.aneel.gov.br/aplicacoes/capacidadebrasil/OperacaoCapacidadeBrasil.cfm $>$ Acesso em 10 de junho de 2019.

Barragem. Disponível em <https://www.itaipu.gov.br/energia/barragem $>$.Acesso em 16 de abril de 2019.

BRANCO, Samuel Murgel. O meio ambiente em debate. São Paulo: Moderna,1997.

BRASIL. Decreto-Lei no 3.365 de 21 de junho de 1941. Dispõe sobre desapropriações por utilidade pública. Diário Oficial da República Federativa do Brasil. Brasília, DF,18/07/1941. 
COELHO, André Luiz Nascentes. Caminhos de Geografia - Revista Online.Geomorfologia Fluvial de Rios Impactados por Barragens. Disponível em

<http://www.ig.ufu.br/revista/caminhos.html ISSN 1678-6343> Acesso em 20 de maiode 2019.

CUNHA, Sandra B. Geomorfologia Fluvial. In: CUNHA, S.B.; GUERRA, A.J.T. (orgs.) Geomorfologia exercícios técnicas e aplicações. 2. ed. Rio de Janeiro: BertrandBrasil, 2002. p. 157-189. CUNHA, Sandra B. Geomorfologia Fluvial. In: GUERRA.

ECODEBATE. Hidrelétrica de São Manoel. Um empreendimento construído à revelia da lei. Entrevista com integrantes do Fórum Teles Pires. Disponível em $<$ https://www.ecodebate.com.br/2017/11/28/hidreletrica-de-sao-manoelumempreendimentoconstruido-revelia-da-lei-entrevista-com-integrantes-do-forum-teles-pires / > Acesso em 03 de novembro de 2019.

FEARNSIDE, P.M. 2008. Hidrelétricas como "fábricas de metano": O papel dos reservatórios em áreas de floresta tropical na emissão de gases de efeito estufa. Oecologia Brasiliensis 12(1): 100- 115. Disponível em <Dialnet- HidreletricasComoFabricasDeMetano2880900.pdf> Acesso em 08 de julho de 2019.

FEARNSIDE, P.M. 2014. Impacts of Brazil's Madeira River dams: Unlearned lessonsfor hydroelectric development in Amazonia. Environmental Science \& Policy 38: 164-172. https://doi.org/10.1016/j.envsci.2013.11.004. ISSN 1462-9011.

FEARNSIDE, Philip M. Os planos para USINAS hidrelétricas e hidro vias na bacia do Tapajós. Uma combinação que implica a concretização dos piores impactos. Ocekadi : hidrelétricas, conflitos socioambientais e resistência na Bacia do Tapajós / Daniela Fernandes Alarcon, Brent Millikan e Mauricio Torres, organizadores. -- Brasília, DF :International Rivers Brasil ; Santarém, PA : Programa de Antropologia e Arqueologia da Universidade Federal do Oeste do Pará, 2016.

FOLHES Rodrigo. Ritual burocrático de ocupação do território pelo setor elétrico:o caso da avaliação ambiental integrada da bacia do Tapajós. Ocekadi: hidrelétricas, conflitos socioambientais e resistência na Bacia do Tapajós / Daniela Fernandes Alarcon, Brent Millikan e Mauricio Torres, organizadores. -- Brasilia, DF: International Rivers Brasil; Santarém, PA: Programa de Antropologia e Arqueologia da Universidade Federal do Oeste do Pará, 2016.

FONSECA, Igor Ferraz da.A Construção de Grandes Barragens no Brasil, na Chinae na Índia: Similitudes e Peculiaridades dos Processos de Licenciamento Ambiental em Países Emergentes. Disponível em <http://repositorio.ipea.gov.br/bitstream/11058/2037/1/TD_1868.pdf>. Acesso em 15 de junho de 2019

GIONGO, Carmem Regina, MENDES Jussara Maria Rosa. A legitimação da injustiçasocial e ambiental: análise da legislação no campo da construção de hidrelétricas no Brasil.

Disponível em

<http://revistaseletronicas.pucrs.br/fass/ojs/index.php/fass/article/view/29018. > Acesso em 16 de maio de 2019.

GOMES, Romero César; GOUVÊA, Paulo Henrique Vitória . Análises de Percolaçãoe da Estabilidade da Barragem de Contenção de Rejeitos de Conceição, Itabira/MG. In: XIII Congresso Brasileiro de Mecânica dos Solos e Engenharia Geotécnica, 2006, Curitiba. Anais do 
XIII Congresso Brasileiro de Mecânica dos Solose Engenharia Geotécnica, 2006. v. 3. p. 16751680.

MARTINEZ, Alier, J. Justiça Ambiental (local e global) In: CAVALCANTI, C. (Org.) Meio Ambiente, Desenvolvimento Sustentável e Políticas Públicas. São Paulo: Cortez, 1999. p. 215-231.

Movimento dos Atingidos por Barragens - MAB .Os licenciamentos ambientais de mentirinha. Disponível em < https://www.mabnacional.org.br/artigo/os-licenciamentosambientais-mentirinha $>$ Acesso em 27 de junho de 2019.

Movimento dos Atingidos por Barragens - MAB. Ditadura na barranca dos rios brasileiros: perseguição e criminalização de militantes da luta contra as barragens. Disponível em $<$ https://www.mabnacional.org.br/artigo/ditadura-na-barranca-dos-rios- brasileiros-persegui-ecriminaliza-militantes-da-luta-contra-ba> Acesso em 24 de maiode 2019.

Movimento dos Atingidos por Barragens - MAB. Queremos energia limpa deverdade. Água e energia não são mercadorias! Disponível em

$<$ http://www.mabnacional.org.br/artigo/queremos-energia-limpa-verdade> Acesso em 24 de maio de 2019.

OMOTO. Prefácio. Ocekadi : hidrelétricas, conflitos socioambientais e resistência na Bacia do Tapajós / Daniela Fernandes Alarcon, Brent Millikan e Mauricio Torres, organizadores. -- Brasília, DF :International Rivers Brasil ; Santarém, PA : Programa de Antropologia e Arqueologia da Universidade Federal do Oeste do Pará, 2016.

ROGERIO, Marcele Scapinet. al., $\mathbf{O}$ conflito na construção de hidrelétricas: desafiospara enfrentar as divergências no processo de construção de um empreendimento hidrelétrico. Disponível em <http://www.ambito-

juridico.com.br/site/?n_link=revista_artigos_leitura\&artigo_id=20573> Acesso em 15 de fevereiro de 2019.

SANTOS, Marco Aurélio dos, et.al., Emissões de gases de efeito estufa por reservatórios de hidrelétricas. Localización: Oecologia Brasiliensis, ISSN-e 1981-9366, Vol. 12, Nº. 1, 2008 (Ejemplar dedicado a: Ciclo do carbono em ambientes aquáticos continentais brasileiros). Disponível em $<$ https://dialnet.unirioja.es/servlet/articulo?codigo=2880904>. Acesso em 23 de abril de2019.

SCHREIBER, Gerhard. Usinas hidrelétricas. Rio de Janeiro: ENGEVIX, 1977.

SNEDDON, Christopher. Concrete revolution: large dams, Cold War geopolitics, and the US Bureau of Reclamation. Chicago: University of Chicago Press, 2015.

SOUZA JÚNIOR, Wilson Cabral de. Tapajós: do rio à luz. Ocekadi: Hidrelétricas, conflitos socioambientais e resistência na Bacia do Tapajós / Daniela Fernandes Alarcon, Brent Millikan e Mauricio Torres, organizadores. -- Brasília, DF: InternationalRivers Brasil; Santarém, PA: Programa de Antropologia e Arqueologia da UniversidadeFederal do Oeste do Pará, 2016.

ZAGONEL, Letícia De Bittencourt. Avaliação do Impacto das Barragens na Variabilidade e Estruturação Genética de PimelodusMaculatusLacepède, 1803(Siluriformes, Pimelodidae) do Rio São Francisco. Disponível em 
<https://www.acervodigital.ufpr.br/bitstream/handle/1884/18394/Dissertacao\%20Letici $\mathrm{a} \% 20 \mathrm{de} \% 20$ Bittencourt $\% 20$ Zagonel.pdf?sequence=1> Acesso em 05 de março de 2019.

ZHOURI, Andréa. OLIVEIRA, Raquel. Desenvolvimento, Conflitos Sociais eViolência no Brasil Rural: o caso das usinas hidrelétricas. Disponível em

<http://w.scielo.br/pdf/asoc/v10n2/a08v10n2.pdf> Acesso em 04 de abril de 2019.

Recebido em: 28 de abril de 2020.

Aprovado em: 03 de novembro de 2020. 